ARTICLE

Received 29 Oct 2015 | Accepted 5 Jan 2016 | Published 4 Feb 2016

DOI: $10.1038 /$ ncomms10623

OPEN

\title{
Development of novel FP-based probes for live-cell imaging of nitric oxide dynamics
}

Emrah Eroglu¹, Benjamin Gottschalk¹, Suphachai Charoensin ${ }^{1}$, Sandra Blass' ${ }^{1}$, Helmut Bischof ${ }^{1}$, Rene Rost ${ }^{1}$, Corina T. Madreiter-Sokolowski , Brigitte Pelzmann², Eva Bernhart1, Wolfgang Sattler ${ }^{1}$, Seth Hallström ${ }^{3}$, Tadeusz Malinski ${ }^{4}$, Markus Waldeck-Weiermair ${ }^{1}$, Wolfgang F. Graier ${ }^{1}$ \& Roland Malli ${ }^{1}$

Nitric oxide (NO•) is a free radical with a wide range of biological effects, but practically impossible to visualize in single cells. Here we report the development of novel multicoloured fluorescent quenching-based $\mathrm{NO} \bullet$ probes by fusing a bacteria-derived $\mathrm{NO} \bullet$-binding domain close to distinct fluorescent protein variants. These genetically encoded $\mathrm{NO} \cdot$ probes, referred to as geNOps, provide a selective, specific and real-time read-out of cellular $\mathrm{NO}^{\bullet}$ dynamics and, hence, open a new era of $\mathrm{NO}^{\bullet}$ bioimaging. The combination of geNOps with a $\mathrm{Ca}^{2+}$ sensor allowed us to visualize $\mathrm{NO}^{\bullet}$ and $\mathrm{Ca}^{2+}$ signals simultaneously in single endothelial cells. Moreover, targeting of the $\mathrm{NO}^{\bullet}$ probes was used to detect $\mathrm{NO}^{\bullet}$ signals within mitochondria. The geNOps are useful new tools to further investigate and understand the complex patterns of $\mathrm{NO}^{\bullet}$ signalling on the single (sub)cellular level.

\footnotetext{
${ }^{1}$ Institute of Molecular Biology and Biochemistry, Center of Molecular Medicine, Medical University of Graz, Harrachgasse 21/III, 8010 Graz, Austria. ${ }^{2}$ Institute of Biophysics, Center of Physiological Medicine, Medical University of Graz, Harrachgasse 21/IV, 8010 Graz, Austria. ${ }^{3}$ Institute of Physiological Chemistry, Center of Physiological Medicine, Medical University of Graz, Harrachgasse 21/II, 8010 Graz, Austria. ${ }^{4}$ Nanomedical Research Laboratory, Department of Chemistry and Biochemistry, Ohio University, 350 West State Street, Athens, Ohio 45701, USA. Correspondence and requests for materials should be addressed to R.M. (email: roland.malli@medunigraz.at).
} 
T he nitric oxide radical $\left(\mathrm{NO}^{\bullet}\right)$ is one of the most studied molecule ${ }^{1}$. The interest in $\mathrm{NO}^{\bullet}$ is based on the important roles this radical plays in the chemical industry, in environmental ecology and, above all, in biology, where it represents one of the most versatile mediators in the (cardio-)vascular, nervous and immune systems ${ }^{2}$. Recent studies indicate that $\mathrm{NO}^{\bullet}$ is also a crucial messenger in tumour cell signalling ${ }^{3}$, plant-microbe interactions ${ }^{4}$ and the development of resistance of bacteria against antibiotics ${ }^{5}$. The wide range of physiological and pathological effects of $\mathrm{NO}^{\bullet}$ are partially induced by the reactivity of the molecule, which is able to modify biomolecules including proteins, lipids and nucleic acids ${ }^{6}$. In addition, $\mathrm{NO}^{\bullet}$ works as a signalling molecule via binding to metalloproteins with specific iron(II) or zinc(II)-containing $\mathrm{NO}^{\bullet}$-binding domains. In these domains, $\mathrm{NO}^{\bullet}$ reversibly interacts with the metal ion and thereby modulates the conformation and activity of the whole signalling protein ${ }^{7}$. Although the fundamental roles of $\mathrm{NO}^{\bullet}$ in biology have been established undoubtedly, many questions remain unanswered, because of limitations of the methods available to detect $\mathrm{NO}^{\bullet}$ in biological samples ${ }^{8}$. Multiple methods to determine $\mathrm{NO}^{\bullet}$ concentrations including organ assays ${ }^{9}$, cell assays ${ }^{10}$, enzymatic assays ${ }^{11}$, electrochemical microelectrodes ${ }^{12}$, spectroscopic measurements ${ }^{13}$ and fluorescent probes $^{14,15}$ have been developed. However, despite the availability of such a broad range of $\mathrm{NO}^{\bullet}$ detection techniques, research activities designed to investigate the complex metabolism and signalling patterns of $\mathrm{NO}^{\bullet}$ in physiology and pathology suffer from the lack of practicable methods for intracellular, single-cell $\mathrm{NO}^{\bullet}$ detection $^{8}$. To overcome this limitation, we aimed to develop genetically encoded fluorescent probes that specifically and directly respond to $\mathrm{NO}^{\bullet}$, thus providing a quantifiable and real-time readout of cellular $\mathrm{NO}^{\bullet}$ dynamics. Therefore, we designed, produced and characterized various genetically encoded $\mathrm{NO}^{\bullet}$ probes (geNOps) by selecting a suitable $\mathrm{NO}^{\bullet}$-binding domain that was conjugated with differently coloured fluorescent protein (FP) variants. We assumed that specific $\mathrm{NO}^{\bullet}$ binding close to FP in such constructs considerably influences the fluorescence signal by affecting the electron density within certain amino acids forming the chromophore. In this study, we demonstrate that such fluorescent chimeras, referred to as geNOps, represent a completely novel class of $\mathrm{NO}^{\bullet}$ indicators that allow direct imaging of (sub)cellular $\mathrm{NO}^{\bullet}$ dynamics in real time.

\section{Results}

Generation of differently coloured geNOps. Out of a limited number of known $\mathrm{NO}^{\bullet}$-binding domains, we selected the GAF domain of the enhancer-binding protein NorR, a transcription factor of the enteric bacterium Escherichia coli ${ }^{16,17}$, for the development of fluorescent geNOps. Being bacteria-derived, the GAF domain of NorR was assumed not to interfere with signalling pathways in higher cells. In addition, the bacterial GAF domain is a small, simply built and specific NO ${ }^{\bullet}$-binding domain with a non-haem iron(II) centre ${ }^{17}$, which appears suitable for bringing the $\mathrm{NO}^{\bullet}$ radical in close vicinity to the chromophore of a conjugated FP. Computational calculation of the three-dimensional structure of a chimeric construct, which consists of a single FP fused to the $\mathrm{N}$ terminus of the GAF domain, predicted that $\mathrm{NO}^{\bullet}$ binds close to the $\mathrm{FP}$ chromophore and might thereby affect fluorescence (Fig. 1a). On the basis of this computation, we produced five different geNOps with different approved FP variants covering a broad colour range (Fig. 1b). To test whether $\mathrm{NO}^{\bullet}$ binding to such chimeras affects the fluorescence of the conjugated FPs dependently or independently from their structure and origin, the used FP variants were either mutated versions of the Aequorea-derived wild-type green fluorescent protein (GFP; super enhanced cyan fluorescent protein (ECFP) ${ }^{18}$ in cyan geNOp (C-geNOp) and enhanced GFP (EGFP) ${ }^{19}$ in green geNOp (G-geNOp)) or circularly permuted FP variants $\left(\mathrm{GEM}^{20}\right.$ in mint green geNOp (M-geNOp) and circularly permuted Venus ${ }^{19}$ in yellow geNOp (Y-geNOp)) or a Coral-derived FP (monomer Kusabira orange $\mathrm{mKO}_{\mathrm{k}}$ (ref. 21) in orange geNOp (O-geNOp)) (Fig. 1b).

Characterization of geNOps in living cells. The impact of $\mathrm{NO}^{\bullet}$ on the fluorescence intensity of the different FP variants within geNOps was examined in HeLa cells expressing these differently coloured chimeras. As expected, expression rates of geNOps in HeLa cells were comparable to those of other genetically encoded probes and FPs alone (Supplementary Fig. 1), demonstrating that the novel protein-based NO probes are not cytotoxic. To supply the GAF domain of the expressed constructs with sufficient iron(II) $\left(\mathrm{Fe}^{2+}\right)$ required for $\mathrm{NO}^{\bullet}$ binding ${ }^{16,22}$, HeLa cells were incubated in a medium containing $\mathrm{Fe}^{2+}$ fumarate and vitamin $\mathrm{C}$ for $10 \mathrm{~min}$ before fluorescence microscopy. This procedure did not affect the morphology, viability and metabolic activity of different cell types (Supplementary Fig. 2), indicating that the usability of geNOps is not limited by iron(II) supplementation. Addition of NOC-7, a potent $\mathrm{NO}^{\bullet}$ donor $^{15}$ via a perfusion system to the microscope bath, instantly reduced the fluorescence intensity of all the differently coloured geNOps by $7-18 \%$ with a high signal-to-noise ratio (Fig. 1c; Supplementary Video 1). A strong linear correlation between the basal fluorescence and the $\mathrm{NO}^{\bullet}$-induced quenching effect was observed over a large range of fluorescence intensity (Supplementary Fig. 3). This is an important feature of the non-ratiometric probes for simple absolute quantification of cellular $\mathrm{NO}^{\bullet}$ concentrations by normalization (Supplementary Note 1). Removal of NOC-7 completely restored fluorescence, demonstrating the full reversibility of the quenching effect of $\mathrm{NO}^{\bullet}$ on the different FP variants in the responding chimeras (Fig. 1c-e,g; Supplementary Video 1). These results proved that fusion of the bacterial $\mathrm{NO}^{\bullet}$-binding GAF domain to $\mathrm{FP}$ variants results in C-geNOp, M-geNOp, G-geNOp, Y-geNOp and O-geNOp (Fig. 1b), allowing imaging of cellular $\mathrm{NO}^{\bullet}$ dynamics in real time and in a multichromatic manner. Experiments using sodium nitroprusside (SNP), another $\mathrm{NO}^{\bullet}$-producing compound in cells $^{23}$, showed homogenous signals in response to a number of consecutive NO ${ }^{\bullet}$ donor pulses (Supplementary Fig. 4), indicating that geNOps are highly stable sensors that enable the recording of extensive $\mathrm{NO}^{\bullet}$ fluctuations over long time. The consecutive addition and removal of different concentrations of NOC-7 $(1-100 \mu \mathrm{M})$ revealed that the differently coloured geNOps respond in a concentration-dependent manner (Fig. 1e,f) with similar sensitivities (Fig. 1f). The effector concentration for half-maximum response of NOC-7 to induce fluorescence quenching of geNOps was found to be between 50 and $94 \mathrm{nM}$ (Fig. 1f; Supplementary Table 1). Considering the short half-time of NOC-7 (ref. 24) and $\mathrm{NO}^{\bullet}$ (ref. 25), these results indicate that geNOps are suitable to recording cellular $\mathrm{NO}^{\bullet}$ concentrations in the low physiological $\mathrm{nM}$ range. However, oxidation of $\mathrm{Fe}^{2+}$ to $\mathrm{Fe}^{3+}$ by hydrogen peroxide $\left(\mathrm{H}_{2} \mathrm{O}_{2}\right)$ (Supplementary Fig. 5 ) or a suboptimal supply of geNOps with $\mathrm{Fe}^{2+}$ (Supplementary Fig. 6) significantly reduced the response to the $\mathrm{NO}^{\bullet}$ donor. These findings support the idea that nitrosylation of $\mathrm{Fe}^{2+}$ of the non-haem iron(II) centre within the GAF domain is essential to induce fluorescence quenching of the attached FP. We further confirmed the $\mathrm{Fe}^{2+}$-dependent $\mathrm{NO}^{\bullet}$-sensing mechanism of geNOps by generating a mutant lacking the arginines at position 75 (deletion) and 81 (R81G), which are 


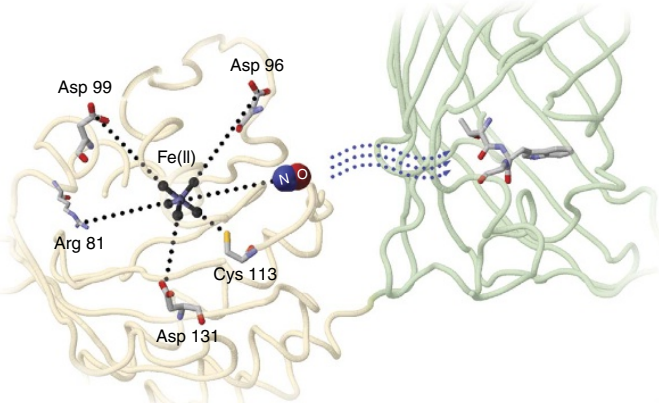

b

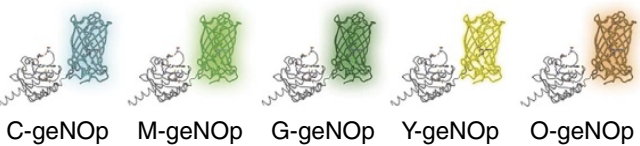

c

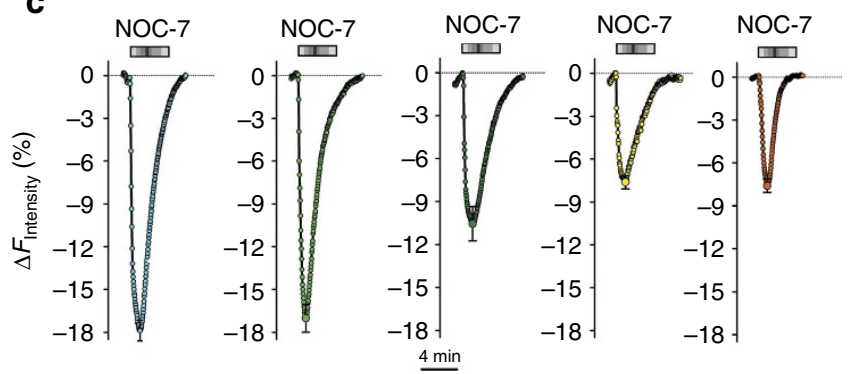

d

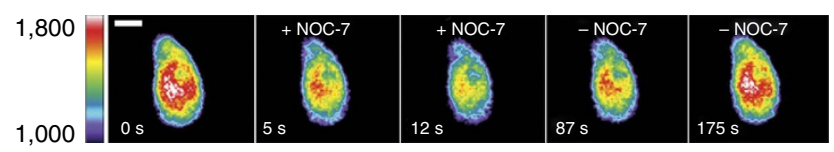

e

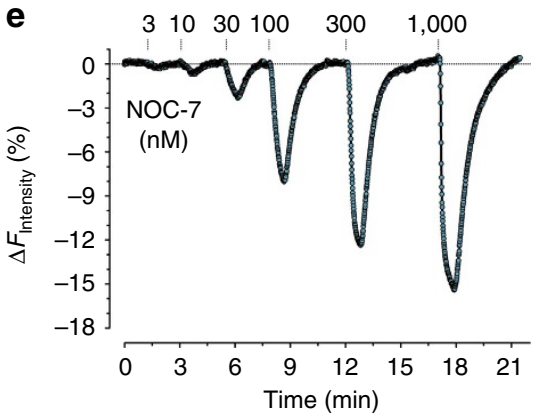

f

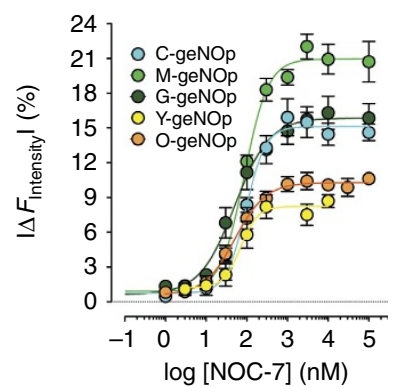

g

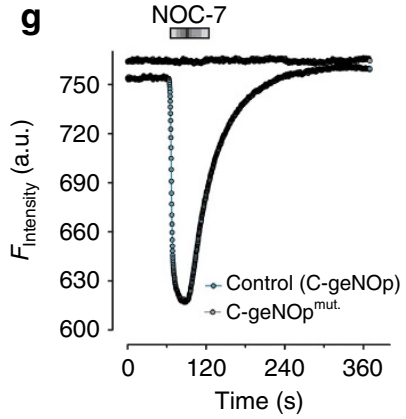

h

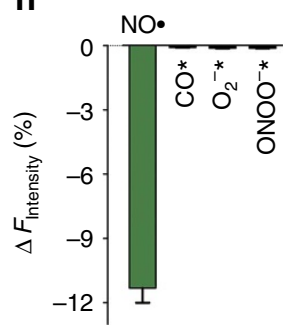

Figure 1 | Fusion of the bacterial NO•-binding GAF domain to fluorescent proteins, resulting in differently coloured fluorescent quenching-based NO probes, the geNOps. (a) Predicted three-dimensional structure of geNOps. (b) Schematic overview of differently coloured geNOps. (c) Average curves (mean \pm s.e.m.) over time of normalized delta fluorescence signals in $\%$ of the differently coloured geNOps signals in response to $10 \mu \mathrm{M}$ NOC-7 ( $n=10$ for C-geNOp cyan curve; $n=12$ for M-geNOp light green curve; $n=11$ for G-geNOp dark-green curve; $n=13$ for Y-geNOp yellow curve; $n=9$ for O-geNOp orange curve). Experiments were performed using HeLa cells. (d) Representative pseudo-coloured images of a HeLa cell expressing O-geNOp before cell treatment $(0 \mathrm{~s}$ ), upon addition of $10 \mu \mathrm{M} \mathrm{NOC-7} \mathrm{(5} \mathrm{and} 12 \mathrm{~s}$ ) and upon the removal of NOC-7 ( 87 and $175 \mathrm{~s}$ ). Scale bar, $10 \mu \mathrm{m}$. See also Supplementary Video 1. (e) Fluorescence intensity change in \% versus time of a single HeLa cell expressing C-geNOp in response to different concentrations of NOC-7. (f) Concentration response curves showing the effects of different NOC-7 concentrations on fluorescence intensities of the differently coloured geNOps that were expressed in HeLa cells. Points represent average values \pm s.e.m.; $n=5$ for C-geNOp, $n=8-11$ for M-geNOp; $n=5-6$ for G-geNOp; $n=3$ for Y-geNOp; $n=3-5$ for O-geNOp. (g) Representative curves showing fluorescence over time of wild-type C-geNOp and C-geNOp mut upon addition of $10 \mu \mathrm{M}$ NOC-7 to HeLa cells. Statistics are shown in Supplementary Fig. 7. (h) Bars representing maximal delta fluorescence signals \pm s.e.m. of G-geNOp expressed in HeLa cells in response to $10 \mu \mathrm{M} \mathrm{NOC}-7$ (NO', green column, $n=26$ ), $100 \mu \mathrm{M}$ of the CO-releasing compound CORM-3 (CO, $n=16), 100 \mu \mathrm{M} \mathrm{KO}_{2}\left(\mathrm{O}_{2}, n=12\right)$ or $100 \mu \mathrm{M}$ peroxynitrite (ONOO $\left.{ }^{-}, n=7\right)$. ${ }^{\star} P<0.05$ versus control using the unpaired $t$-test.

essential for the coordinative binding of $\mathrm{Fe}^{2+}$ in the non-haem iron(II) centre ${ }^{16,17}$ (Supplementary Fig. 7). In contrast to functional geNOps, the fluorescence signal of this mutated construct remained unaffected by the addition of high concentrations of the $\mathrm{NO}^{\bullet}$ donor to cells expressing the mutated probe (Fig. 1g). In line with these findings, increasing the $\mathrm{NO}^{\bullet}$ concentration in cells expressing the same FP variants alone or fused to either $\mathrm{Ca}^{2+}$ - or ATP-binding domains did not impact any of these fluorescence signals (Supplementary Fig. 8). This indicates that the $\mathrm{NO}^{\bullet}$ radical, even at high concentrations, does not directly affect the fluorescence of FPs. Consistent with this assumption, the addition of NOC-7 did not affect the fluorescence of HyPer, a genetically encoded $\mathrm{H}_{2} \mathrm{O}_{2}$ probe ${ }^{26}$, which showed a clear reduction of fluorescence upon cell treatment with $50 \mu \mathrm{M} \quad \mathrm{H}_{2} \mathrm{O}_{2} \quad$ (Supplementary Fig. 9). Contrariwise, the fluorescence of $\mathrm{C}$-geNOp was considerably quenched by adding NOC-7 but remained unaffected by administration of $\mathrm{H}_{2} \mathrm{O}_{2}$, showing that geNOps do not respond to cellular $\mathrm{H}_{2} \mathrm{O}_{2}$ fluctuations (Supplementary Fig. 9). To further examine the selectivity of geNOps, compounds chemically related to $\mathrm{NO}^{\bullet}$, including carbon monoxide, superoxide and peroxynitrite, were tested. While the used compounds have been shown to at least partially diffuse across the plasma membrane of cells ${ }^{27-29}$, none of these compounds affected the geNOp fluorescence signal in HeLa cells, demonstrating the high selectivity of the sensor in its exclusive response to intracellular $\mathrm{NO}^{\bullet}$ fluctuations (Fig. 1h). As superoxide anions as well as peroxynitrite might not fully penetrate into cells, we also generated a glycosylphosphatidylinositol (GPI)-anchored C-geNOp (GPI-C-geNOp), which localized at the outer surface of the cell membrane (Supplementary Fig. 10a,b). GPI-C-geNOp strongly responded to the addition of $\mathrm{NO}^{\bullet}$ donors (Supplementary Fig. 10c), indicating that the probe remains functional upon targeting to the outer surface of the plasma membrane. Addition of neither superoxide anions nor peroxynitrite significantly affected the fluorescence of GPI-C-geNOp (Supplementary Fig. 10c), confirming the high $\mathrm{NO}^{\bullet}$ selectivity of geNOps. Moreover, the responsiveness of geNOps to $\mathrm{NO}^{\bullet}$ remained at different intracellular $\mathrm{pH}$ values (Supplementary Fig. 11). Due to the general $\mathrm{pH}$ sensitivity of $\mathrm{FPs}^{19}$, the fluorescence of geNOps was altered upon changes of the intracellular proton concentration 
(Supplementary Fig. 12). O-geNOp containing $\mathrm{mKO}_{\mathrm{k}}$ (ref. 21) showed the highest $\mathrm{pH}$ stability between $\mathrm{pH} 7$ and 9 (Supplementary Fig. 12). Expectedly, the pH-dependent effects on the fluorescence intensity of functional C-geNOp and G-geNOp were equal to that of respective $\mathrm{NO}^{\bullet}$-insensitive mutated constructs (Supplementary Fig. 13). Thus, we assume that a clear discrimination between real cellular $\mathrm{NO}^{\bullet}$ and $\mathrm{pH}$ fluctuations is possible by comparing measurements using on the one hand functional $\mathrm{NO}^{\bullet}$ probes and on the other hand mutated geNOps (geNOp ${ }^{\text {mut }}$ ) under the same experimental conditions.

Generation of mitochondria-targeted geNOps. Several studies point to a particular role of $\mathrm{NO}^{\bullet}$ within mitochondria ${ }^{30}$. However, real-time detection of $\mathrm{NO}^{\bullet}$ signals within mitochondria in intact cells has not been accomplished so far. Accordingly, we tested whether mitochondria-targeted geNOps (mt-geNOps) allow to overcome this limitation. For this purpose, we constructed $\mathrm{mtC}$-geNOp and $\mathrm{mtG}$-geNOp by fusing a mitochondria-targeting sequence to the $\mathrm{N}$ terminus of respective probes. Expression of $\mathrm{mtC}$-geNOp and $\mathrm{mtG}$-geNOp showed clear organelle localization of the constructs (Fig. 2a). Both mtC-geNOp and mtG-geNOp co-localized with MitoTrackerRed, confirming correct targeting of the $\mathrm{NO}^{\bullet}$ probes to mitochondria (Supplementary Fig. 14). To test the functionality of mitochondria-targeted geNOps, cells expressing these probes were treated with NOC-7. Similar to the non-targeted probes, addition of the $\mathrm{NO}^{\bullet}$ donor instantly and significantly reduced the fluorescence intensity of $\mathrm{mtC}$-geNOp and $\mathrm{mtG}-\mathrm{geNOp}$ (Fig. 2b), demonstrating the efficiency of mitochondria-targeted geNOps. The $\mathrm{NO}^{\bullet}$-induced quenching of the fluorescence of mt-geNOps was again boosted by $\mathrm{Fe}^{2+}$ supplementation (Fig. 2b). Mitochondria targeting did not affect the quality of geNOps to detect consecutive pulses of $\mathrm{NO}^{\bullet}$ over a long period of time (Fig. 2c). In addition, both $\mathrm{mtC}$-geNOp and mtG-geNOp showed similar sensitivities and responsiveness to different concentrations of NOC-7 compared with the respective non-targeted $\mathrm{NO}^{\bullet}$ probes (Fig. 2d). These data prove that mitochondria-targeted geNOps can be used for live-cell imaging of $\mathrm{NO}^{\bullet}$ signals within these cellular organelles.

Imaging of cellular $\mathrm{NO}^{\bullet}$ signals in response to $\mathrm{NO}^{\bullet}$ donors. We next applied different $\mathrm{NO}^{\bullet}$ donors to visualize and compare $\mathrm{NO}^{\bullet}$ dynamics on the single cell level (Fig. 3). For this purpose, we used low-molecular-weight $\mathrm{NO}^{\bullet}$ donors and $S$-nitroso human serum albumin (S-NO-HSA) with a high capacity to stably release $\mathrm{NO}^{\bullet}$ over time, due to its long half-life ${ }^{31}$. While $30 \mathrm{~s}$ perfusion of HeLa cells with NOC-7 and SNP evoked almost identical cellular $\mathrm{NO}^{\bullet}$ signals, PROLI NONOate, a more instable compound ${ }^{32}$, led to a more transient $\mathrm{NO}^{\bullet}$ increase, with the highest peak under these conditions (Fig. 3a). In HeLa cells, addition of NOC-7 to the image medium induced clear variances of the strength of $\mathrm{NO}^{\bullet}$ signals within cells on the same dish, while the average responses among different dishes were nearly homogeneous (Fig. 3b). These findings might point to cell-to-cell heterogeneities in the $\mathrm{NO}^{\bullet}$ scavenging capacity of HeLa cells. Addition of S-NO-HSA induced a distinctly slower increase of cellular $\mathrm{NO}^{\bullet}$ levels compared with the fast $\mathrm{NO}^{\bullet}$-liberating low-molecular-weight $\mathrm{NO}^{\bullet}$ donors (Fig. 3c; Supplementary Fig. 15, left panel). SNP, which is known to liberate $\mathrm{NO}^{\bullet}$ by reacting with biomolecules in the cell ${ }^{23}$, increased cellular $\mathrm{NO}^{\bullet}$ levels only at high concentrations ( $\geq 1 \mathrm{mM}$; Supplementary Fig. 15, right panel), pointing to a weak capacity of this compound to release $\mathrm{NO}^{\bullet}$. These experiments demonstrate that geNOps enable the precise characterization of highly diverse $\mathrm{NO}^{\bullet}$ donors by providing a a

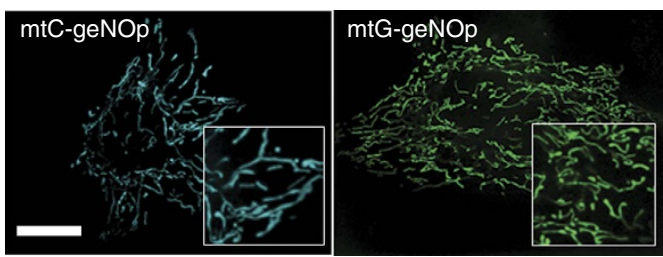

C

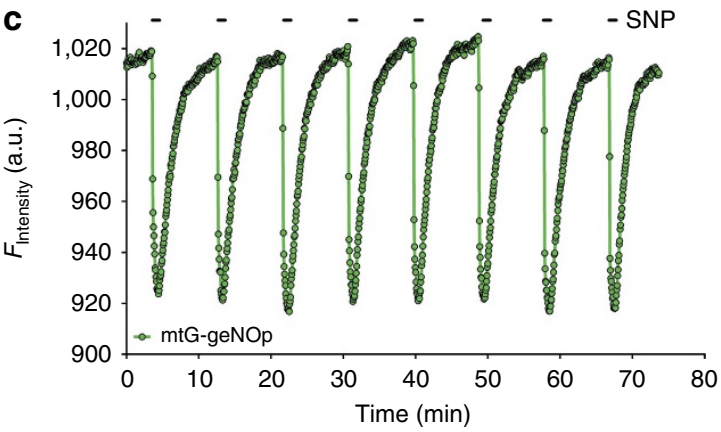

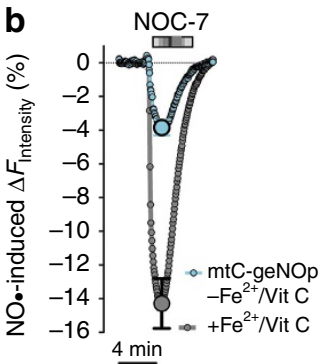

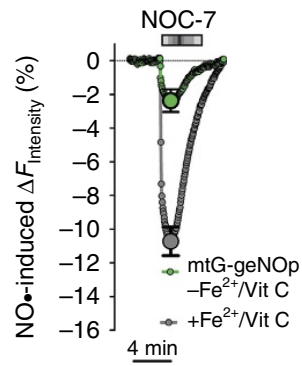

d

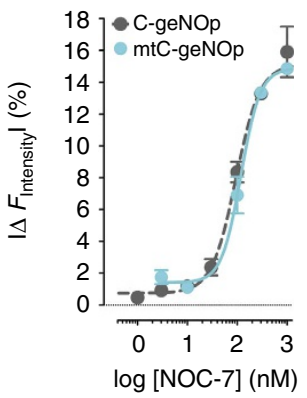

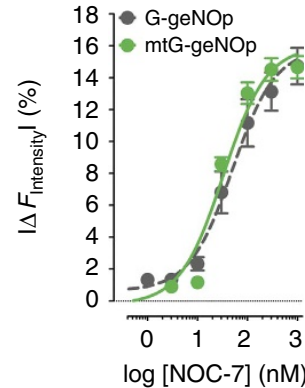

Figure 2 | The properties of geNOps remain unaffected upon mitochondria targeting. (a) Confocal images of HeLa cells expressing either mtC-geNOp (left image) or $\mathrm{mtG}$-geNOp (right image). Scale bar, $10 \mu \mathrm{m}$. (b) Normalized average curves \pm s.e.m. of mtC-geNOp (left panel) and mtG-geNOp (right panel) signals with ( $n=4$ for $\mathrm{mtC}$-geNOp; $n=7$ for $\mathrm{mtG}$-geNOp) and without ( $n=5$ for $\mathrm{mtC}$-geNOp; $n=4$ for mtG-geNOp) iron(II)/vitamin C pretreatment. Experiments were performed using HeLa cells. (c) Representative original curve showing fluorescence over time of mtG-geNOp expressed in HeLa cells in response to consecutive applications of $3 \mathrm{mM} \mathrm{SNP}(n=3)$. (d) Concentration response curves showing the effects of different NOC-7 concentrations on fluorescence intensities of either mtC-geNOp (left panel, cyan curve, $n=4$ ) versus C-geNOp (left panel, grey curve, for $n$ see Fig. 1f) or mtG-geNOp (right panel, green curve, $n=6$ ) versus G-geNOp (right panel grey curve, for $n$ see Fig. 1f). Experiments were performed using HeLa cells. Points represent average values \pm s.e.m. 

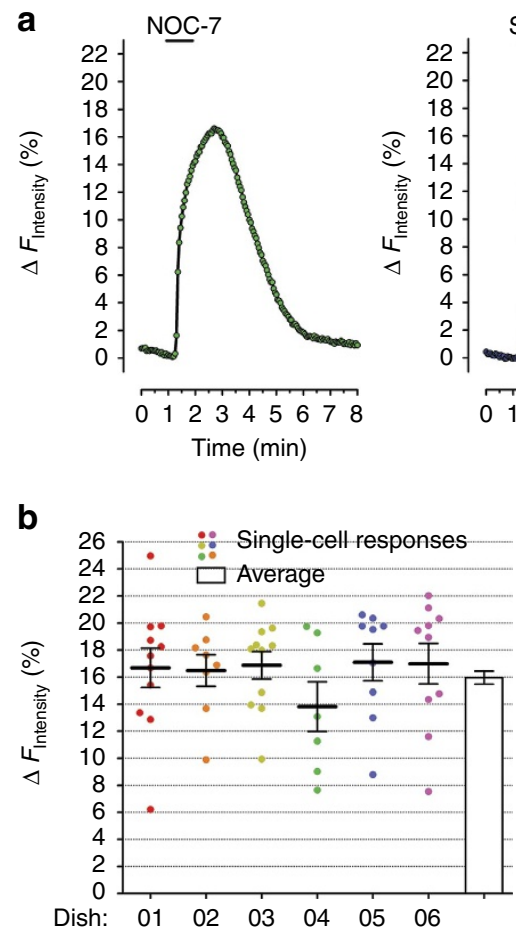
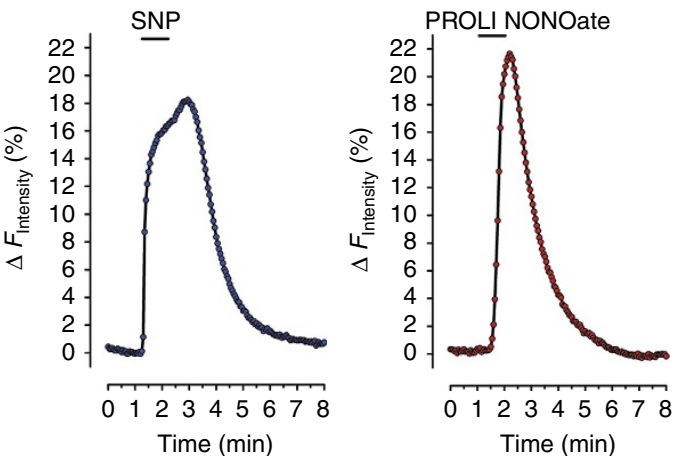

C

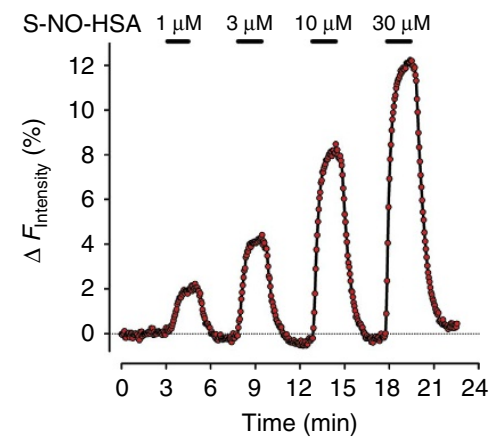

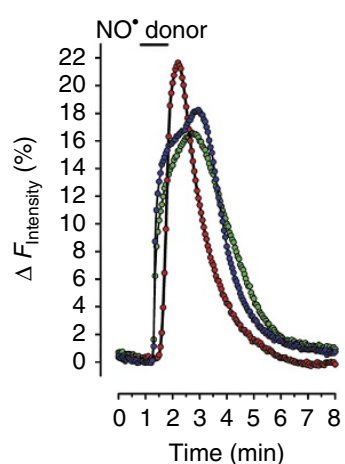

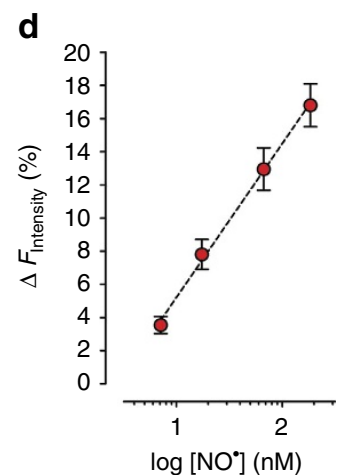

Figure 3 | Imaging of cellular NO• dynamics with geNOps in response to different NO•-liberating molecules. (a) Representative single HeLa cell NO• dynamics in response to $1 \mu \mathrm{M}$ NOC-7, $1 \mathrm{mM}$ SNP or $1 \mu \mathrm{M}$ PROLI NONOate. Cells expressing C-geNOp were imaged. Inverted curves (1-F/FO in \%) are shown. Average curves with s.e.m. are shown in Supplementary Fig. 15. (b) Scatter dot plot showing maximal single-cell C-geNOp signals in response to $10 \mu \mathrm{M}$ NOC-7 on different dishes. White column represents the normalized average \pm s.e.m. C-geNOp signal of all single HeLa cells $(n=67)$.

(c) Intracellular $\mathrm{NO}^{\bullet}$ dynamics of a single HeLa cell expressing C-geNOp in response to different concentrations of S-NO-HSA (curve is inverted). (d) Respective $\Delta F_{\text {Intensity }}$ mean values \pm s.e.m. are blotted against NO concentrations that are released by $1,3,10$ and $30 \mu \mathrm{M} \mathrm{S-NO-HSA}(n=6)$. NO• released by S-NO-HSA was quantified using a porphyrinic nanosensor (for details see Supplementary Fig. 16 and methods).

reliable, real-time readout of the actual $\mathrm{NO}^{\bullet}$ dynamics on the single-cell level in response to these compounds. Such information is valuable for an efficient testing of newly developed, $\mathrm{NO}^{\bullet}$-releasing and $\mathrm{NO}^{\bullet}$-scavenging drugs. On the basis of the capacity of S-NO-HSA to stably release constant amounts of $\mathrm{NO}^{\bullet}$, this compound was further used to estimate the concentration reflected by geNOps signals. For this purpose, the free $\mathrm{NO}^{\bullet}$ concentrations released by different concentrations of S-NO-HSA were determined using a highly sensitive $\mathrm{NO}^{\bullet}$ porphyrinic nanosensor (Supplementary Fig. 16) and plotted against respective geNOp responses (Fig. 3d). This analysis was further used to estimate the physiological $\mathrm{NO}^{\bullet}$ concentration in single endothelial cells. Moreover, the approach was used to estimate the on and off kinetics of C-geNOp to respond to $\mathrm{NO}^{\bullet}$ (Supplementary Note 2).

Correlations of $\mathrm{NO}^{\bullet}$ signals with cell functions. To further demonstrate the applicability of geNOps in other cell types, the probes were expressed in primary embryonic ventricular cardiomyocytes. By measuring geNOps signals, we could show that the addition of nitric oxide donors allowed us to evoke controllable cellular $\mathrm{NO}^{\bullet}$ elevations in this cell type (Supplementary Fig. 17). Hence, we further used this approach to mimic and investigate the paracrine effect of exogenously generated $\mathrm{NO}^{\bullet}$ on spontaneous $\mathrm{Ca}^{2}+$ signals in single cardiomyocytes. Elevation of $\mathrm{NO}^{\bullet}$ did not prevent $\mathrm{Ca}^{2+}$ transients but temporally correlated with a moderate increase of the frequency of $\mathrm{Ca}^{2}+$ oscillations (Fig. 4a), confirming that $\mathrm{NO}^{\bullet}$ is a regulator of myocardiac function ${ }^{33}$. In an additional set of experiments, we used the geNOps technology to relate elevated cellular $\mathrm{NO}^{\bullet}$ levels with the motility of individual glioblastoma cells (Fig. 4b-d). Short treatment of the cells with a mixture of PROLI NONOate and NOC-7 highly increased the cellular NO• concentration (Fig. 4b). This procedure did not affect the overall cell motility (Fig. 4c) but markedly reduced the radius of cell movements (Fig. 4d), indicating that high $\mathrm{NO}^{\bullet}$ pulses might impair the metastatic spread of glioblastoma cells.

Imaging of $\mathrm{Ca}^{2+}$-induced $\mathrm{NO}^{\bullet}$ formation in endothelial cells. We tested the utility of geNOps in visualizing physiologically triggered, $\mathrm{Ca}^{2+}$-activated enzymatic $\mathrm{NO}^{\bullet}$ generation in the human umbilical vein cell line EA.hy926, which is known to solidly express the endothelial nitric oxide synthase (eNOS) ${ }^{34}$. $\mathrm{Ca}^{2+}$ mobilization with different concentrations of the physiological inositol 1,4,5-trisphosphate ( $\left.\mathrm{IP}_{3}\right)$-generating agonist histamine resulted in clear responses of functional (Fig. 5a), but not mutated geNOps (Supplementary Fig. 18), demonstrating endogenous $\mathrm{Ca}^{2+}$-triggered concentrationdependent $\mathrm{NO}^{\bullet}$ production in single endothelial cells. The $\mathrm{NO}^{\bullet}$ signals in endothelial cells were reduced in the absence of $\mathrm{Ca}^{2+}$ entry (Supplementary Fig. 19), confirming the importance of $\mathrm{Ca}^{2}+$ influx for sustained eNOS activity ${ }^{35}$. Moreover, as expected the histamine-evoked $\mathrm{NO}^{\bullet}$ signals were strongly diminished in the presence of NOS inhibitors (Fig. 5b,c; Supplementary Fig. 20). While cell treatment either with the $\mathrm{IP}_{3}$-generating agonist histamine or ATP induced almost identical patterns of $\mathrm{NO}^{\bullet}$ elevations, the sarco/endoplasmic reticulum $\mathrm{Ca}^{2+}$-ATPase (SERCA) inhibitor thapsigargin evoked a clearly delayed, slower 
a
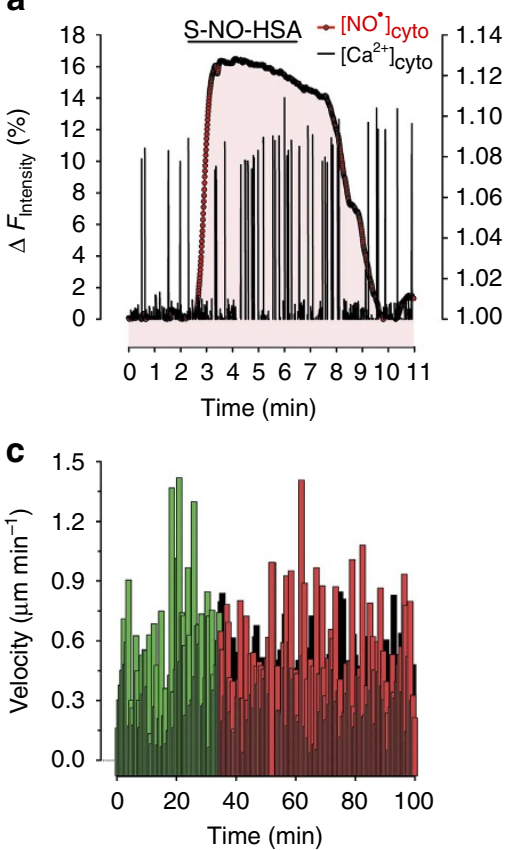

b $\left[\mathrm{NO}^{*}\right]_{\mathrm{cyt}}$
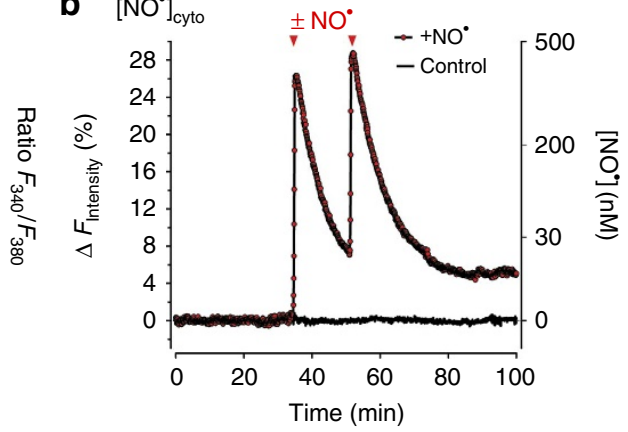

d

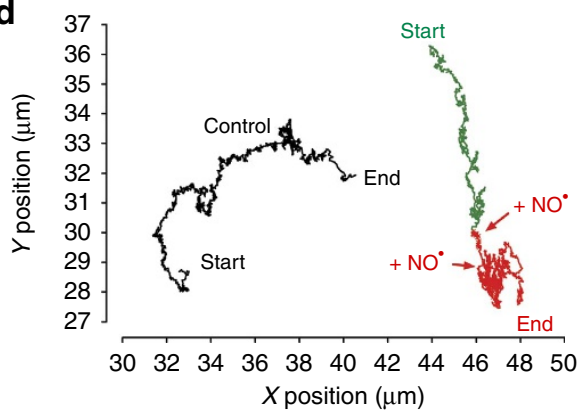

Figure 4 | Live-cell imaging of NO• signals and cell functions in primary cardiomyocytes and glioblastoma cells using geNOps. (a) Curves represent representative simultaneous recordings of cellular $\mathrm{Ca}^{2+}$ (black ratio curve) and $\mathrm{NO}{ }^{\bullet}$ (red inverted curve) signals over time of a single fura-2/am-loaded embryonic ventricular cardiomyocyte expressing G-geNOp. The cell was treated with $30 \mu \mathrm{M} \mathrm{S-NO-HSA}$ in the presence of extracellular Ca ${ }^{2+}$ using a perfusion system $(n=4)$. (b) Representative recordings of cellular NO ${ }^{\bullet}$ dynamics (red inverted curve, $\left.n=4\right)$ of human glioblastoma cells (U87-MG cells) expressing C-geNOp. Cells were either treated with a mixture of $10 \mu \mathrm{M}$ PROLI NONOate and $10 \mu \mathrm{M} \mathrm{NOC-7}$ (red curve) or remained untreated (control cell, black curve). (c) Cell velocity of glioblastoma cells in $\mu \mathrm{m} \mathrm{min}^{-1}$ extracted from the $X / Y$ positions over time of a control cell (black columns) and a cell treated with $\mathrm{NO}^{\bullet}$ donors as indicated in $\mathbf{b}$ and $\mathbf{d}$. (d) Graphs represent $X / Y$ positions of glioblastoma cells over time as indicated in $\mathbf{b}$ and $\mathbf{c}$.

and weaker $\mathrm{NO}^{\bullet}$ rise in endothelial cells (Fig. 5d). To correlate the temporal patterns of cytosolic $\mathrm{NO}^{\bullet}$ and $\mathrm{Ca}^{2+}$ dynamics in individual cells, red-shifted geNOps (either G-geNOp or O-geNOp) were co-imaged with fura-2, an ultraviolet excitable chemical $\mathrm{Ca}^{2+}$ indicator ${ }^{36}$ (Fig. 5e,f). This approach unveiled a temporal delay and slower kinetics of cellular $\mathrm{NO}^{\bullet}$ dynamics compared with respective cytosolic $\mathrm{Ca}^{2}+$ signals elicited by addition of either histamine (Fig. 5e; Supplementary Fig. 21) or the $\mathrm{Ca}^{2+}$ ionophore ionomycin (Fig. 5f). However, these experiments also highlighted a strict correlation between the enzymatic $\mathrm{NO}^{\bullet}$ production and cytosolic $\mathrm{Ca}^{2+}$ signals in single endothelial cells.

Imaging of $\mathrm{NO}^{\bullet}$ within mitochondria of endothelial cells. Next, we used endothelial cells expressing mitochondria-targeted G-geNOp to test whether endogenously generated $\mathrm{NO}^{\bullet}$ is detectable within these organelles. Cell treatment with ATP elicited clear mtG-geNOp signals, which were strongly reduced by the addition of L-NAME and recovered robustly in the presence of NOC-7 (Fig. 6a,c). The fluorescence of the $\mathrm{NO}^{\bullet}$-insensitive $\mathrm{mtG}^{-g e N O p}{ }^{\text {mut }}$ did, however, not respond to any of these treatments under the same experimental conditions (Fig. 6a). Respective geNOps signals in endothelial cells expressing non-targeted cytosolic G-geNOp did not significantly differ from the mitochondrial responses (Fig. 6b,c) These data demonstrated that NOS activation upon $\mathrm{Ca}^{2+}$ mobilization with an $\mathrm{IP}_{3}$-generating agonist also yield a significant elevation of $\mathrm{NO}^{\bullet}$ within mitochondria in single endothelial cells. Next, we performed multichannel imaging of mitochondria-targeted and cytosolic geNOps in the same single cells to correlate $\mathrm{NO}^{\bullet}$ signals within both compartments. While the fluorescence of
mtC-geNOp could be completely separated from the fluorescence of cytosolic G-geNOp using confocal microscopy (Fig. 6d), a spectral overlay between ECFP- and EGFP-based geNOps was observed using a wide-field imaging system (Supplementary Fig. 22). Hence, we applied spectral unmixing ${ }^{37}$, which eliminated the spectral crosstalk between mitochondria-targeted and cytosolic geNOps (Supplementary Fig. 22; Supplementary Note 3). To validate this procedure, endothelial cell coexpressing C-geNOp ${ }^{\text {mut }}$ and $\mathrm{mtG}^{-g e N O p}$ were treated first with ATP and subsequently with NOC-7. Neither ATP nor NOC-7 significantly affected the fluorescence of the non-targeted cytosolic C-geNOp ${ }^{\text {mut }}$, while in the same cell the mitochondriatargeted $\mathrm{mtG}$-geNOp showed clear responses, confirming complete separation of respective fluorescence channels (Supplementary Fig. 23). Co-imaging of mtC-geNOp and cytosolic G-geNOp revealed identical ATP-triggered $\mathrm{NO}^{\bullet}$ signals in both compartments of a single individual endothelial cell (Fig. 6e). The same result was obtained in cells expressing both mtG-geNOp and cytosolic C-geNOp (Supplementary Fig. 23). These data indicate that upon eNOS activation $\mathrm{NO}^{\bullet}$ instantly and efficiently increases both in the cytosol and within the mitochondrial matrix. In addition, our data demonstrate that upon removal of the agonist, $\mathrm{NO}^{\bullet}$ declines with the same kinetics in both compartments (Fig. 6e; Supplementary Fig. 23).

\section{Discussion}

Although the importance of $\mathrm{NO}^{\bullet}$ as a key regulator of diverse cell functions is well accepted, little is known about the actual dynamics of this radical within single cells and subcellular compartments $^{8}$. The lack of practicable techniques that provide a selective, direct and real-time readout of single (sub)cellular $\mathrm{NO}^{\bullet}$ 
a

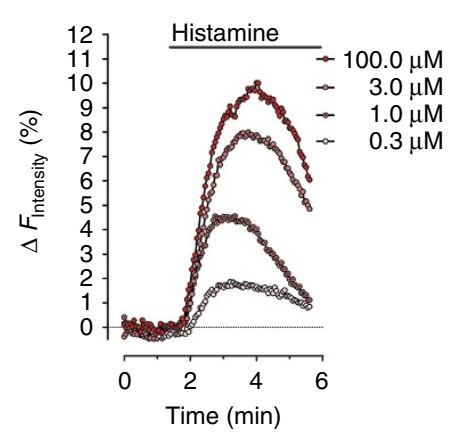

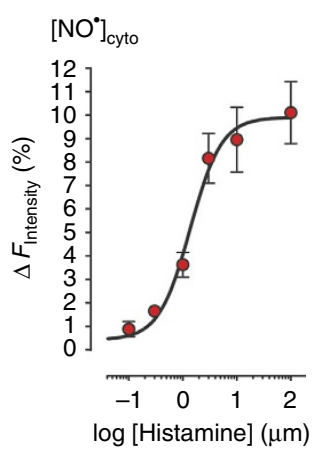

b

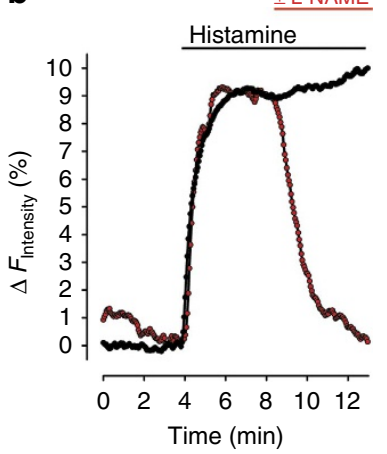

C

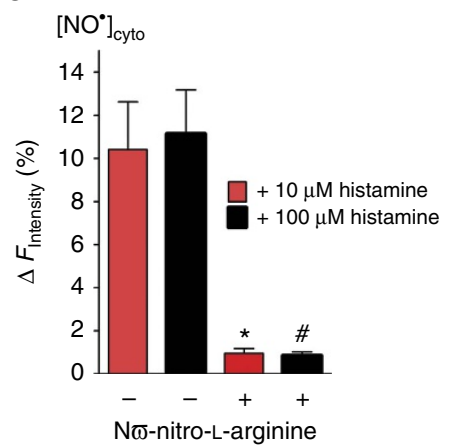

d

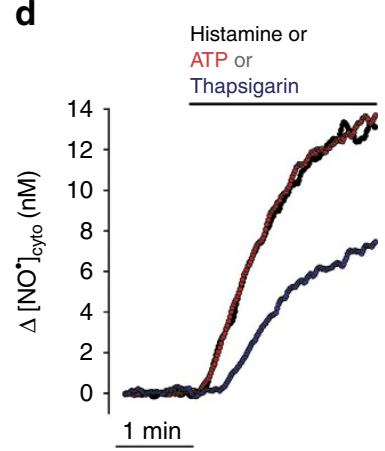

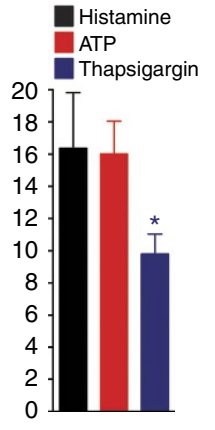

e

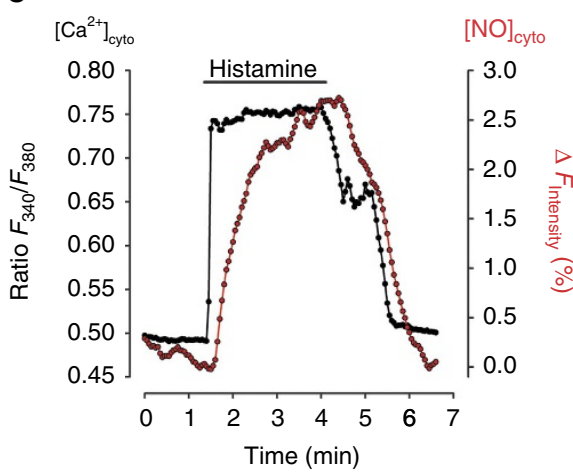

$\mathbf{f}$
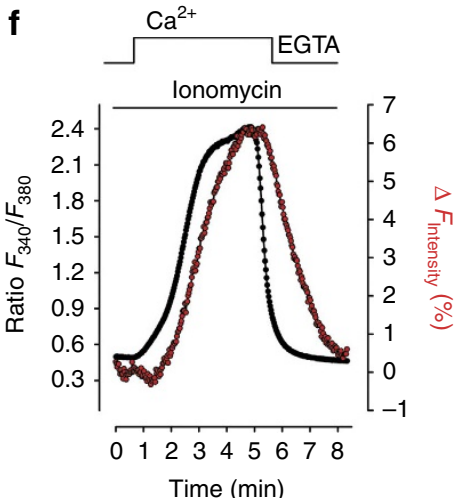

Figure 5 | Live-cell imaging of $\mathbf{C a}^{2+}$-triggered $\mathbf{N O}$ production in signals endothelial cells. (a) Single endothelial cell (EA.hy 926 cells) NO• responses upon cell treatment with different concentrations of histamine (right panel, $0.3 \mu \mathrm{M} ; 1.0 \mu \mathrm{M} ; 3.0 \mu \mathrm{M} ; 100 \mu \mathrm{M}$ histamine, inverted curves are shown) in the absence of extracellular $\mathrm{Ca}^{2+}$. For the concentration response curve (right panel), cells expressing C-geNOp were stimulated with $0.1 \mu \mathrm{M}(n=6)$, $0.3 \mu \mathrm{M}$ $(n=6), 1.0 \mu \mathrm{M}(n=7), 3.0 \mu \mathrm{M}(n=7), 10.0 \mu \mathrm{M}(n=7)$ or $100.0 \mu \mathrm{M}(n=12)$ histamine, yielding an effector concentration for half-maximum response of $1.4(0.8-2.5) \mu \mathrm{M}$. Red points represent average values \pm s.e.m. (b) Cellular NO` dynamics of EA.hy 926 cells expressing C-geNOp. Cells were stimulated with $100 \mu \mathrm{M}$ histamine in $\mathrm{Ca}^{2}+$ containing buffer for 9 min under control conditions (black inverted curve, $n=4$ ) or during stimulation, $1 \mathrm{mM}$ L-NAME was added (red inverted curve, $n=9$ ). (c) Columns represent maximal G-geNOps signals \pm s.e.m. in response to either 10 (red columns) or $100 \mu \mathrm{M}$ (black columns) histamine under control conditions ( $n=5$ for both histamine concentrations) and in the presence of the NOS inhibitor ( $1 \mathrm{mM}$; $n=10$ for both histamine concentrations). ${ }^{\star} P<0.05$ versus control (10 $\mu \mathrm{M}$ histamine); $\# P<0.05$ versus control $(100 \mu \mathrm{M}$ histamine). $P$ values were calculated using unpaired $t$-test. (d) Average $\mathrm{NO}^{\bullet}$ curves over time (right panel) and statistics of the maximal cytosolic $\mathrm{NO}^{\bullet}$ increase (columns representing average values \pm s.e.m. in the left panel) in EA.hy 926 cells in response to $30 \mu \mathrm{M}$ histamine (black curve, black column, $n=16$ ), $30 \mu \mathrm{M}$ ATP (red curve and red column, $n=20$ ) or $1 \mu \mathrm{M}$ thapsigargin (blue curve, blue column, $n=15$ ). Endothelial cells expressing C-geNOps were used ${ }^{\star} P<0.05$ versus histamine/ATP using unpaired $t$-test. (e) Curves represent simultaneous recordings of cellular $\mathrm{Ca}^{2+}$ (black ratio curve) and NO (red inverted curve) signals over time of a single fura-2/am-loaded endothelial cell expressing O-geNOp as shown in Supplementary Fig. 21. The cell was stimulated with $100 \mu \mathrm{M}$ histamine in the presence of extracellular $\mathrm{Ca}^{2+}$. (f) Simultaneous recordings of cellular $\mathrm{Ca}^{2+}$ (black ratio curve) and $\mathrm{NO}^{\bullet}$ (red inverted curve) signals over time of a single fura-2/am-loaded endothelial cell expressing G-geNOp. During imaging, the cell was treated with $1 \mu \mathrm{M}$ ionomycin in the absence (1 mM EGTA) and presence of $2 \mathrm{mM} \mathrm{Ca}^{2+}$.

dynamics hampered investigations in this regard ${ }^{38}$, since $\mathrm{NO}^{\bullet}$ has been discovered to function as an endothelium-derived relaxing factor in 1987 (ref. 39). The differently coloured geNOps, we have introduced in this study, can be used for real-time tracking of $\mathrm{NO}^{\bullet}$ in single cells and subcellular compartments such as mitochondria. The key feature of geNOps is that these probes selectively bind $\mathrm{NO}^{\bullet}$, which induces a significant quenching of the intensity of the FP within the probe. This concentration-dependent effect occurs immediately upon $\mathrm{NO}^{\bullet}$ binding and is fully reversible and repeatable so that geNOps can be used to visualize (sub)cellular $\mathrm{NO}^{\bullet}$ signals dynamically and over a long period of time.

Convincing measurements of single cell $\mathrm{NO}^{\bullet}$ signals in real time with other small chemical fluorescent $\mathrm{NO}^{\bullet}$ indicators such as 4,5-diaminofluorescein diacetate have not been accomplished so far. While such probes can be easily loaded into cells, $\mathrm{NO}^{\bullet}$ and other reactive species irreversibly modify the chemical structure of these fluorescent indicators so that they do not provide a selective and actual readout of cellular $\mathrm{NO}^{\bullet}$ signals ${ }^{40}$. Moreover, small chemical $\mathrm{NO}^{\bullet}$ probes have been shown to be cytotoxic and can aggregate within certain cell compartments, both of which considerably limit their range of usability ${ }^{40,41}$. Hence, it is very important to develop novel improved $\mathrm{NO}^{\bullet}$ probes that overcome these limitations. In contrast to small chemical indicators, genetically encoded fluorescent probes are usually not toxic for cells and can be efficiently localized to virtually any subcellular compartments ${ }^{42,43}$. The development of protein-based sensors is, however, challenging 44 . Usually, this requires fusion of proper sensing domains to one or more FPs in a way that a measurable signal can be obtained upon the specific binding of the analyte of interest. While we used a well-characterized bacteria-derived $\mathrm{NO}^{\bullet}$-binding domain to generate functional fluorescent geNOps, Pearce et al. used metallothionein, a cysteine-rich small protein with unknown functions, to detect the production of $\mathrm{NO}^{\bullet}$ in intact cells ${ }^{45}$. In their study, the authors could confirm that $\mathrm{NO}^{\bullet}$ interacts with 
a

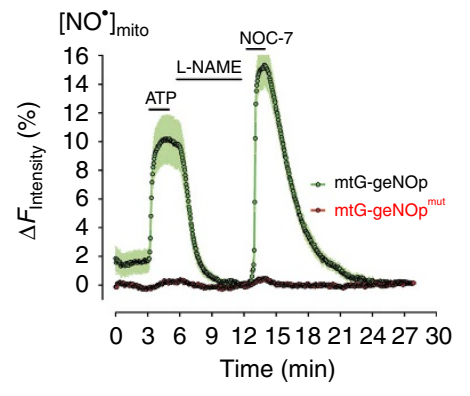

d

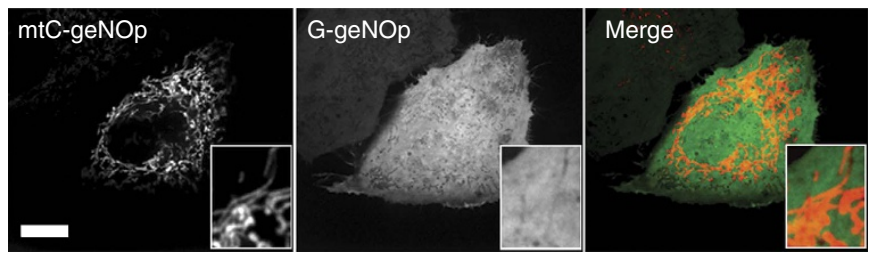

b

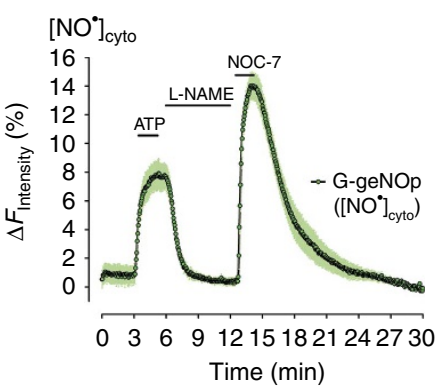

C

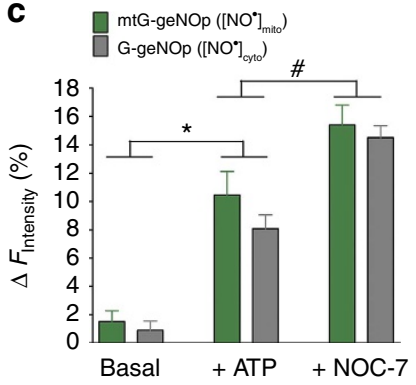

e

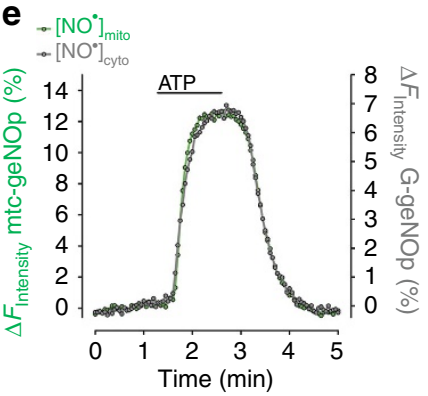

Figure 6 | Visualization of NO^ signals within mitochondria of signals endothelial cells. (a) Average curves \pm s.e.m. showing mitochondrial NO• signals measured with $\mathrm{mtG}$-geNOp expressed in EA.hy926 cells (green curve, $n=7$ ) and respective signals obtained with mtG-geNOp mut (red curve, $n=7$ ). Cells were treated first with $100 \mu \mathrm{M}$ ATP, then with $1 \mathrm{mM} \mathrm{L-NAME}$ and subsequently with $10 \mu \mathrm{M}$ NOC-7. (b) Average curves \pm s.e.m. showing cytsolic NO• signals measured with G-geNOp expressed in EA.hy926 cells (green curve, $n=5$ ). As shown in a, cells were treated first with $100 \mu \mathrm{M}$ ATP, then with $1 \mathrm{mML}$-NAME and subsequently with $10 \mu \mathrm{M}$ NOC-7. (c) Columns represent maximal average values of curves shown in $\mathbf{a}$ and $\mathbf{b}$. ${ }^{\star} P<0.05$ versus basal. $\# P<0.05$ versus + ATP. $P$ values were calculated using unpaired $t$-test. (d) Confocal images of endothelial cells expressing both mtC-geNOp (left image) and cytosolic G-geNOp (middle image). Scale bar, $10 \mu \mathrm{m}$. (e) Representative simultaneous recordings of mtC-geNOp (grey curve) and cytosolic G-geNOp (green curve) signals over time in a single EA.hy926 cell in response to $100 \mu \mathrm{M}$ ATP.

metallothionein, and that $\mathrm{NO}^{\bullet}$ binding affects the protein conformation, which results in increased Förster resonance energy transfer (FRET) between terminally located FPs. However, this FRET-based probe only provides a readout of a single $\mathrm{NO}^{\bullet}$ elevation, as it does not respond to $\mathrm{NO}^{\bullet}$ in a reversible manner. Moreover, the probe releases metal ions upon $\mathrm{NO}^{\bullet}$ binding that might impact cell functions. Actually, only few $\mathrm{NO}^{\bullet}$-binding proteins in mammalians, plants and bacteria have been identified and characterized so far. Accordingly, the number of known putative $\mathrm{NO}^{\bullet}$-sensing domains for the development of protein-based $\mathrm{NO}^{\bullet}$ probes is quite limited. In mammalians, the soluble guanylate cyclase (sGC) is the dominant $\mathrm{NO}^{\bullet}$ responsive target, which reversibly binds $\mathrm{NO}^{\bullet}$ via a haem iron centre ${ }^{46}$. $\mathrm{NO}^{\bullet}$ binding to sGC stimulates the generation of cyclic GMP (cGMP), an intracellular second messenger that regulates multiple cell signalling pathways ${ }^{47}$. Sato et al. generated an indirect $\mathrm{NO}^{\circ}$ probe based on $\mathrm{NO}^{\bullet}$ binding to sGC and the subsequent cGMP determination via a FRET-based sensor ${ }^{15}$. Although this probe was used to image $\mathrm{NO}^{\bullet}$ in the low nano molar range, the technique has some limitations. First of all, the fluorescent probe has a small dynamic range, measures cGMP and not $\mathrm{NO}^{\bullet}$ directly. In addition, the practicality of the usage of this sensor is rather poor as it depends on the simultaneous expression of two different constructs, which have to dimerize to form the working probe. As the dimerization of the alpha and beta subunit of the sGC is essential for $\mathrm{NO}^{\bullet}$ binding to the haem iron centre of this protein, we considered sGC as a suboptimal candidate for the development of fluorescent geNOps that directly sense $\mathrm{NO}^{\bullet}$.

In line with a recent study that showed the importance of iron(II) in the non-haem $\mathrm{NO}^{\bullet}$-binding domain of norR for the functionality of this bacterial transcription factor ${ }^{17}$, our data clearly indicate that sufficient iron(II) within the bacteria-derived GAF domain of geNOps is essential to obtain full $\mathrm{NO}^{\bullet}$ responsiveness of all the differently coloured probes. Iron(II) supplementation was essential to significantly increase the dynamic range of all geNOps in different cell types. We established a fast, simple and non-harmful treatment to supply geNOps-expressing cells with efficient amounts of iron(II), which under normal cell culture conditions is provided rather poorly ${ }^{48}$. While iron(II) supplementation did not cause any obvious problems when using the geNOps technology in cultured cells, this procedure might limit the applicability of geNOps. It might be challenging to increase the iron(II) amount of expressed geNOps when using this technology in vivo. On the other hand, the iron(II) homeostasis in living organisms might be anyway sufficient to supply expressed geNOps with iron(II) adequately. However, further experiments are necessary to investigate whether or not geNOps are useful tools to image $\mathrm{NO}^{\bullet}$ signals also in vivo.

The basal fluorescence of geNOps was affected by $\mathrm{pH}$ changes as FPs are $\mathrm{pH}$ sensitive ${ }^{19}$. However, the responsiveness of geNOps to $\mathrm{NO}^{\bullet}$ remained over a huge $\mathrm{pH}$ range, indicating that these probes can be also used in alkaline and acidic compartments such as mitochondria or endo- and lysosomes, respectively. Indeed, we could demonstrate that mitochondria-targeted geNOps remain fully functional. Nevertheless, due to the $\mathrm{pH}$ sensitivity of FPs, acute $\mathrm{pH}$ changes within cells ${ }^{49}$ might complicate correct interpretation of geNOps signals. In this study, we, hence, performed key experiments using mutated probes that did not respond to $\mathrm{NO}^{\bullet}$, but kept their $\mathrm{pH}$ sensitivity. Using these probes under the same experimental conditions allowed us to estimate that the geNOps signals reflect real (sub)cellular $\mathrm{NO}^{\bullet}$ dynamics and were not due to acute $\mathrm{pH}$ changes. The development of novel optimized geNOps that contain other bright and $\mathrm{pH}$-stable FPs would be a direct approach to circumvent this problem. Considering the high number of additionally available and 
newly developed FP variants ${ }^{19}$ with improved properties as well as novel techniques to generate and test whole libraries of altered probes $^{20}$, such efforts will certainly yield in advanced geNOps in near future.

Due to the high signal-to-noise ratio of geNOps, we were able to study both the dynamics of (sub)cellular $\mathrm{NO}^{\bullet}$ signals in response to even low concentrations of different $\mathrm{NO}^{\bullet}$ donors and endogenously $\mathrm{Ca}^{2+}$-triggered $\mathrm{NO}^{\bullet}$ production in endothelial cells. Our experiments revealed that $\mathrm{Ca}^{2}+$ mobilization using the two different $\mathrm{IP}_{3}$-generating agonists histamine and ATP evoked identical $\mathrm{NO}^{\bullet}$ increases in endothelial cells, while the SERCA inhibitor thapsigargin was less effective to elevate $\mathrm{NO}^{\bullet}$ production. These results are consistent with other reports that show clear differences in the kinetics and amplitude of cytosolic $\mathrm{Ca}^{2+}$ signals in response to either $\mathrm{IP}_{3}$-generating agonists or SERCA inhibitors $^{50-52}$. The combination of fura-2 with red-shifted geNOps demonstrated that $\mathrm{Ca}^{2+}$ signals temporally correlate with respective $\mathrm{NO}^{\bullet}$ transients in endothelial cells. These findings point to a fast on and off kinetic of the $\mathrm{Ca}^{2+}$-regulated eNOS activity and displayed how tight this enzyme is under the control of the cytosolic $\mathrm{Ca}^{2+}$ concentration. Targeting geNOps into the mitochondrial matrix in combination with cytosolic geNOps enabled us to simultaneously monitor $\mathrm{NO}^{\bullet}$ dynamics in both compartments in single individual endothelial cells. These experiments showed that $\mathrm{Ca}^{2+}$-triggered $\mathrm{NO}^{\bullet}$ signals are identical in both compartments, confirming the high capability of $\mathrm{NO}^{\bullet}$ to diffuse across biomembranes. It has been suggested that mitochondria are able to generate $\mathrm{NO}^{\bullet}$ autonomously under certain conditions ${ }^{53}$. Moreover, the existence of NOS located within mitochondria has been proposed, while the respective protein has not been identified explicitly so $\mathrm{far}^{54}$. Our experiments shown in this manuscript neither confirm nor argue against a mitochondrial NO production, but the geNOps technology will be very useful to further investigate this and other remaining important question in the field of $\mathrm{NO}^{\bullet}$-related cell biology.

In summary, we have generated differently fluorescent geNOps and have demonstrated their suitability to single-live-cell $\mathrm{NO}^{\bullet}$ imaging in different cell types. These novel tools will enhance the high-resolution investigation of intracellular $\mathrm{NO}^{\bullet}$ generation, degradation, as well as diffusion under physiological and pathological conditions. This, in turn, will improve our understanding of the complex cellular metabolism and signalling patterns of one of nature's most reactive and versatile messengers.

\footnotetext{
Methods

Cloning of geNOps. Briefly, cloning was performed according to standard procedures and all products were verified by sequencing. Genomic DNA of E. Coli DH10 $\alpha$ was isolated by a DNA extraction protocol using phenol/chloroform extraction followed by ethanol precipitation and subsequent solubilization in $30 \mu \mathrm{l}$ deionized water. The bacterial DNA was used as a template to isolate the GAF subunit of the NorR transcription factor in a PCR with the following primers: forward 5'-GGCATCGATATGAGTTTTTCCGTTGATGTGC-3' that adds a ClaI restriction site and reverse $5^{\prime}$-GGCAAGCTTAAGGGGACAAGCCAATCATCT- ${ }^{\prime}$ including a stop codon and a HindIII site. To obtain various single FP-based geNOps, the PCR product of the GAF domain was $\mathrm{C}$ terminally fused to a super ECFP, a blue-green emitting FP $(\mathrm{GEM})^{20}$, an EGFP, a circularly permuted Venus or a $\mathrm{mKO}_{\mathrm{k}}$ via $\mathrm{ClaI}$ and HindIII in a mammalian expression vector pcDNA3.1(-) (Invitrogen, Austria). To construct the $\mathrm{NO}^{\bullet}$-insensitive probes (C-geNOp ${ }^{\text {mut }}$ and G-geNOp ${ }^{\text {mut }}$ ), the two argingines at positions 75 and 81 of the GAF domain were mutated by a two-step PCR protocol using two additional primers forward $5^{\prime}$ AGCGCTGGAAGCGATTGCCGCCG- ${ }^{\prime}$ and reverse $5^{\prime}$-CCGGCGGCGGC AATCGCTTCCAGCGCT- $3^{\prime}$. For targeting geNOps into mitochondria, two COX VIII mitochondria-targeting sequences were added to the $\mathrm{N}$ terminus of respective constructs. To target C-geNOp to the outer surface of the plasma membrane, a membrane leading sequence of the human cadherin 13 ( 24 amino acids) was added to the $\mathrm{N}$ terminus and the GPI-anchor sequence of cadherin 13 (coding for 26
} amino acids) were fused to the $\mathrm{C}$ terminus of $\mathrm{C}$-geNOp, respectively.
Chemicals and buffer solutions. Cell culture materials were obtained from PAA laboratories (Pasching, Austria). Histamine hydrochloride, Iron(II)fumarate, 2,5-Di-t-butyl-1,4-benzohydroquinone, ethylene glycol tetraacetic acid (EGTA), Tris- $\mathrm{HCl}$, monensin, nigericin, CORM-3, L-NAME and potassium superoxide were purchased from Sigma Aldrich (Vienna, Austria). NOC-7 and PROLI NONOate were from Santa Cruz (San Diego, USA). ATP was obtained from Roth (Graz, Austria). Peroxynitrite was from Cayman Chemical (Michigan, USA). SNP was purchased from Gatt-Koller (Absam, Austria). Ionomycin was obtained from Abcam (Cambridge, UK).

Before the experiments, cells were washed and maintained for $20 \mathrm{~min}$ in a HEPES-buffered solution (storage buffer) containing $138 \mathrm{mM} \mathrm{NaCl}, 5 \mathrm{mM} \mathrm{KCl}$, $2 \mathrm{mM} \mathrm{CaCl}_{2}, 1 \mathrm{mM} \mathrm{MgCl}, 1 \mathrm{mM}$ HEPES, $2.6 \mathrm{mM} \mathrm{NaHCO} 3,0.44 \mathrm{mM} \mathrm{KH}_{2} \mathrm{PO}_{4}$, $0.34 \mathrm{mM} \mathrm{Na}_{2} \mathrm{HPO}_{4}, 10 \mathrm{mM}$ D-glucose, $0.1 \%$ vitamins, $0.2 \%$ essential amino acids and $1 \%$ penicillin-streptomycin, the $\mathrm{pH}$ was adjusted to 7.4 with $\mathrm{NaOH}$.

During the experiments, cells were perfused in a physiological $\mathrm{Ca}^{2+}$-containing buffer $\left(\mathrm{Ca}^{2+}\right.$ buffer), which consisted of $140 \mathrm{mM} \mathrm{NaCl}, 5 \mathrm{mM} \mathrm{KCl}, 2 \mathrm{mM} \mathrm{CaCl}_{2}$, $1 \mathrm{mM} \mathrm{MgCl} 2,10 \mathrm{mM}$ D-glucose and $1 \mathrm{mM}$ HEPES, the $\mathrm{pH}$ was adjusted to 7.4 with $\mathrm{NaOH}$. For $\mathrm{Ca}^{2+}$-free experiments $1 \mathrm{mM}$ EGTA was added to the perfusion buffer instead of $2 \mathrm{mM} \mathrm{Ca}^{2+}$. Preparation of iron(II) fumarate solution was performed in the $\mathrm{Ca}^{2}+$ buffer by adding $1 \mathrm{mM}$ iron(II) fumarate and $1 \mathrm{mM}$ ascorbic acid and stirring at room temperature in the dark. During the experiments, various NO donors or other pharmacological compounds were applied to the cells using a gravity-based perfusion system connected with a conventional vacuum pump (Chemistry diaphragm pump ME 1C, Vacuubrand, Wertheim, Germany).

Measurement of $\mathrm{NO}^{\bullet}$ release using a poryphyrinic nanosensor. For estimation of $\mathrm{NO}^{\bullet}$ concentrations, release of NO ${ }^{\bullet}$ from S-NO-HSA dissolved in physiological saline was measured with a poryphyrinic nanosensor in a tissue culture bath at identical concentrations as used for geNOp signal imaging. The nanosensor was operated in a three-electrode system, consisting of the sensor working electrode, a platinum wire $(0.1 \mathrm{~mm})$ counter electrode, and a standard calomel reference electrode. The current proportional to concentration was measured by the nanosensor operated in an amperometric mode at a constant potential of $0.65 \mathrm{~V}$. The response time of the nanosensors was $0.1 \mathrm{~ms}$. The $\mathrm{NO}^{\bullet}$ nanosensor was calibrated for the range $1 \mu \mathrm{mol} \cdot \mathrm{L}^{-1}$ using aliquots of a $\mathrm{NO}^{\bullet}$ standard-saturated aqueous solution $\left(1.76 \mathrm{mmoll}^{-1}\right)$. The amperometric signals for NO were recorded with a computer-based Gamry VF600 voltametric analyser.

Equation for $\left[\mathrm{NO}^{\bullet}\right]_{\text {cyto }}$ from respective changes in fluorescence intensities of C-geNOps $(\Delta F)$ was obtained by plotting the respective $\mathrm{NO}^{\bullet}$ concentrations (obtained with the poryphyrinic nanosensor) against $\Delta F_{\text {Intensity }}$ values and fitting the data with a saturation kinetic:

$$
\left[\mathrm{NO} \bullet \text { cyto }=\frac{\Delta F \times K}{\left(\Delta F_{\max }-\Delta F\right)}\right.
$$

where $K$ is the concentration of S-NO-HSA at half maximal response (4.50) and $\Delta F_{\max }$ is the maximal geNOp response (19.16).

Cell culture, transfection and fura-2/AM loading. HeLa cells were grown in DMEM (Sigma Aldrich) containing $10 \%$ fetal bovine serum, $100 \mathrm{U} \mathrm{ml}^{-1}$ penicillin and $100 \mu \mathrm{g} \mathrm{ml}^{-1}$ streptomycin. Culture medium of EA.hy926 cells contained additionally $1 \%$ HAT ( $5 \mathrm{mM}$ hypoxanthin, $20 \mu \mathrm{M}$ aminopterin and $0.8 \mathrm{mM}$ thymidine). Human glioblastoma U87-MG cells were cultured in DMEM supplemented with $10 \%$ fetal bovine serum, $4 \mathrm{mM}$ glutamine, $50 \mathrm{U} \mathrm{ml}^{-1}$ penicillin and $50 \mathrm{mg} \mathrm{ml}^{-1}$ streptomycin. At $60-80 \%$ confluence, cells in $30-\mathrm{mm}$ imaging dishes were transfected with $1 \mathrm{ml}$ of serum- and antibiotic-free medium that had been mixed with $1.5 \mu \mathrm{g}$ of the approprioate plasmid DNA and $3 \mu \mathrm{g}$ of TransFast transfection reagent (Promega). Cells were maintained in a humidified incubator $\left(37^{\circ} \mathrm{C}, 5 \% \mathrm{CO}_{2}, 95 \%\right.$ air) for $16-20 \mathrm{~h}$ before changing back to the respective culture medium. All experiments were performed either 24 or $48 \mathrm{~h}$ after transfection. For dual recordings using fura-2, cells were incubated in storage buffer containing $3.3 \mu \mathrm{M}$ fura-2/AM for $40 \mathrm{~min}$. Before the experiments, cells were incubated $10 \mathrm{~min}$ in the iron(II) fumarate solution.

Culturing embryonic chicken ventricular cardiomyocytes. Ventricular myocytes were isolated from embryonic chick hearts. The hearts of 7-day embryos were removed, and the ventricles were chopped off, minced and transferred to a nominally $\mathrm{Ca}^{2+}$ - and $\mathrm{Mg}^{2+}$-free Hanks' balanced salt solution (HBSS; in mM: $137 \mathrm{NaCl}, 5.4 \mathrm{KCl}, 0.34 \mathrm{Na}_{2} \mathrm{HPO}_{4}, 0.44 \mathrm{KH}_{2} \mathrm{PO}_{4}, 4.2 \mathrm{NaHCO}_{3}$ and 5 glucose, $\mathrm{pH}$ 7.4) containing $0.25 \%$ trypsin (bovine pancreas, Sigma-Aldrich). The suspension was transferred to a shaker bath at $37^{\circ} \mathrm{C}$ for $7 \mathrm{~min}$, afterwards cells were released with mechanical disruption (pipetting) and filtered through a $100-\mu \mathrm{m}$ mesh. HBSS, supplemented with fetal calf serum ( $5 \%$ final concentration), was added to stop trypsin activity. The cell suspension was centrifuged at $100 \mathrm{~g}$ for $5 \mathrm{~min}$ at $4{ }^{\circ} \mathrm{C}$, the supernatant was discarded and the cell pellet was resuspended in fresh trypsin-free HBSS. The centrifugation and resuspension processes were then repeated. After the third time cells were resuspended in M199 cell culture medium (Sigma-Aldrich, supplemented with $4 \%$ fetal calf serum, $2 \%$ horse serum and $0.7 \mathrm{mM}$ glutamine, pH 7.4) to yield a density of $3.5 \times 10^{5}$ cells per ml. 
Live-cell imaging of $\mathrm{NO}^{\bullet}$ concentrations with geNOps. Measurements were performed on two different wide-field imaging systems: an inverted and advanced fluorescent microscope with a motorized sample stage (Till Photonics, Graefling, Germany) was used. The probes were excited via a polychrome V (Till Photonics), and emission was visualized using a $\times 40$ objective (alpha Plan Fluar $40 \times$, Zeiss, Göttingen, Germany), and a charge-coupled device camera (AVT Stringray F145B, Allied Vision Technologies, Stadtroda, Germany). C-geNOp and M-geNOp were excited at $430 \mathrm{~nm}$, G-geNOp and Y-geNOp at $480 \mathrm{~nm}$, and O-geNOp at $515 \mathrm{~nm}$. Emitted light was collected with emission filters CFP emitter $482 / 18 \mathrm{~nm}$, yellow fluorescent protein emitter $514 / 3 \mathrm{~nm}$ or orange fluorescent protein-emitting filter (560dcxr), respectively. In addition, for simultaneous measurements of cytosolic $\mathrm{Ca}^{2+}$, Fura-2 was alternately excited at 340 and $380 \mathrm{~nm}$, and emissions were captured at $515 \mathrm{~nm}$ (515dcxr). For control and acquisition, the Live acquisition 2.0.0.12 software (Till Photonics) was used.

Alternatively, geNOps were visualized on a Nikon eclipse TE300 inverted microscope (Tokyo, Japan) using a $\times 40$ objective (Plan Fluor, Nikon, Vienna or Fluor, Zeiss, Jena, Germany) and fluorescence was recorded with a Spot pursuit charge-coupled device camera (Visitron Systems, Puchheim, Germany). Fura-2 and geNOps were excited as described above, and emissions were collected using emission filter 510WB40 or XF56 (Omega Opticals, Brattleboro, VT, USA). Data acquisition and control were done using the VisiView Premier Acquisition software (Visitron Systems).

Characterization of the pH sensitivity of geNOps. To characterize the $\mathrm{pH}$ sensitivity, HeLa cells expressing C-geNOp were treated using a series of buffers with various $\mathrm{pH}$ values ranging from 5 to 9 . Cells were prepared with $10 \mu \mathrm{M}$ nigericin and $10 \mu \mathrm{M}$ monensin, and $20 \mathrm{mM}$ MES (for $\mathrm{pH}$ 5-6.5), $20 \mathrm{mM}$ HEPES (for $\mathrm{pH} 7-7.5$ ) or $20 \mathrm{mM}$ Tris- $\mathrm{HCl}$ (for $\mathrm{pH}$ 8-9) containing buffer. Cells were additionally stimulated with $10 \mu \mathrm{M}$ NOC-7 at respective $\mathrm{pH}$ values.

Construction of structural models of geNOps. Models of all geNOps were constructed with the online tool Phyre2 (Protein Homology/analogy Recognition Engine V 2.0). Analyses of the predicted proteins were performed with the software DeepView/Swiss Pdb viewer V4.1.0 observed from ExPASy.

Cell velocity measurements. Centre of mass was determined for cells over the whole stack after binearization with an Otzu auto threshold in ImageJ. To deter mine the cell velocity between consecutive positions, following equation was used:

$$
v=\frac{\sqrt{\left(\left|x_{t=1}-x_{t=2}\right|\right)^{2}+\left(\left|y_{t=1}-y_{t=2}\right|\right)^{2}}}{\left|t_{1}-t_{2}\right|}
$$

$(x)$ and $(y)$ are the localization coordinates of the centre of mass at consecutive time points $\left(t_{1}\right)$ and $\left(t_{2}\right)$.

Statistical analysis. Statistical analysis was performed using the GraphPad Prism software version 5.04 (GraphPad Software, San Diego, CA, USA). Analysis of variance and $t$-test were used for evaluation of the statistical significance. $P<0.05$ was defined to be significant. At least three different experiments on different days have been performed for each experimental set-up.

\section{References}

1. SoRelle, R. Nobel prize awarded to scientists for nitric oxide discoveries. Circulation 98, 2365-2366 (1998).

2. Hirst, D. G. \& Robson, T. Nitric oxide physiology and pathology. Methods Mol. Biol. 704, 1-13 (2011).

3. Xu, W., Liu, L. Z., Loizidou, M., Ahmed, M. \& Charles, I. G. The role of nitric oxide in cancer. Cell Res. 12, 311-320 (2002).

4. Mur, L. A. J. et al. Nitric oxide in plants: an assessment of the current state of knowledge. AoB Plants 5, pls052 (2013).

5. Gusarov, I., Shatalin, K., Starodubtseva, M. \& Nudler, E. Endogenous nitric oxide protects bacteria against a wide spectrum of antibiotics. Science 325, 1380-1384 (2009)

6. Pacher, P., Beckman, J. S. \& Liaudet, L. Nitric oxide and peroxynitrite in health and disease. Physiol. Rev. 87, 315-424 (2007).

7. Bredt, D. S. \& Snyder, S. H. Nitric oxide: a physiologic messenger molecule. Annu. Rev. Biochem. 63, 175-195 (1994).

8. Ye, X., Rubakhin, S. S. \& Sweedler, J. V. Detection of nitric oxide in single cells. Analyst 133, 423-433 (2008).

9. Holzmann, S., Kukovetz, W. R., Windischhofer, W., Paschke, E. \& Graier, W. F. Pharmacologic differentiation between endothelium-dependent relaxations sensitive and resistant to nitro-L-arginine in coronary arteries. J. Cardiovasc. Pharmacol. 23, 747-756 (1994).

10. Kuhn, M., Otten, A., Frölich, J. C. \& Förstermann, U. Endothelial cyclic GMP and cyclic AMP do not regulate the release of endothelium-derived relaxing factor/nitric oxide from bovine aortic endothelial cells. J. Pharmacol. Exp. Ther. 256, 677-682 (1991).
11. Combet, S., Balligand, J. L., Lameire, N., Goffin, E. \& Devuyst, O. A specific method for measurement of nitric oxide synthase enzymatic activity in peritoneal biopsies. Kidney Int. 57, 332-338 (2000)

12. Vallance, P. et al. Direct measurement of nitric oxide in human beings. Lancet 346, 153-154 (1995).

13. Hogg, N. Detection of nitric oxide by electron paramagnetic resonance spectroscopy. Free Radic. Biol. Med. 49, 122-129 (2010).

14. Kojima, H. et al. Detection and imaging of nitric oxide with novel fluorescent indicators: diaminofluoresceins. Anal. Chem. 70, 2446-2453 (1998).

15. Sato, M., Hida, N. \& Umezawa, Y. Imaging the nanomolar range of nitric oxide with an amplifier-coupled fluorescent indicator in living cells. Proc. Natl Acad. Sci. USA 102, 14515-14520 (2005).

16. D’Autréaux, B., Tucker, N. P., Dixon, R. \& Spiro, S. A non-haem iron centre in the transcription factor NorR senses nitric oxide. Nature 437, 769-772 (2005).

17. Bush, M., Ghosh, T., Tucker, N., Zhang, X. \& Dixon, R. Transcriptional regulation by the dedicated nitric oxide sensor, NorR: a route towards NO detoxification. Biochem. Soc. Trans. 39, 289-293 (2011).

18. Matsuda, T., Miyawaki, A. \& Nagai, T. Direct measurement of protein dynamics inside cells using a rationally designed photoconvertible protein. Nat. Methods. 5, 339-345 (2008).

19. Shaner, N. C., Steinbach, P. A. \& Tsien, R. Y. A guide to choosing fluorescent proteins. Nat. Methods. 2, 905-909 (2005).

20. Zhao, Y. et al. An expanded palette of genetically encoded $\mathrm{Ca}^{2}$ indicators. Science 333, 1888-1891 (2011).

21. Karasawa, S., Araki, T., Nagai, T., Mizuno, H. \& Miyawaki, A. Cyan-emitting and orange-emitting fluorescent proteins as a donor/acceptor pair for fluorescence resonance energy transfer. Biochem. J. 381, 307-312 (2004).

22. Bush, M. et al. The structural basis for enhancer-dependent assembly and activation of the AAA transcriptional activator NorR. Mol. Microbiol. 95, 17-30 (2015).

23. Grossi, L. \& D’Angelo, S. Sodium nitroprusside: mechanism of NO release mediated by sulfhydryl-containing molecules. J. Med. Chem. 48, 2622-2626 (2005).

24. Maragos, C. M. et al. Complexes of.NO with nucleophiles as agents for the controlled biological release of nitric oxide. Vasorelaxant effects. J. Med. Chem 34, 3242-3247 (1991).

25. Kelm, M. Nitric oxide metabolism and breakdown. Biochim. Biophys. Acta. 1411, 273-289 (1999).

26. Belousov, V. V. et al. Genetically encoded fluorescent indicator for intracellular hydrogen peroxide. Nat. Methods. 3, 281-286 (2006).

27. Chlopicki, S., Olszanecki, R., Marcinkiewicz, E., Lomnicka, M. \& Motterlini, R. Carbon monoxide released by CORM-3 inhibits human platelets by a mechanism independent of soluble guanylate cyclase. Cardiovasc. Res. 71, 393-401 (2006).

28. Marla, S. S., Lee, J. \& Groves, J. T. Peroxynitrite rapidly permeates phospholipid membranes. Proc. Natl Acad. Sci. USA 94, 14243-14248 (1997).

29. Mumbengegwi, D. R., Li, Q., Li, C., Bear, C. E. \& Engelhardt, J. F. Evidence for a superoxide permeability pathway in endosomal membranes. Mol. Cell. Biol. 28, 3700-3712 (2008).

30. Nisoli, E. et al. Mitochondrial biogenesis in mammals: the role of endogenous nitric oxide. Science 299, 896-899 (2003).

31. Hallström, S. et al. S-nitroso human serum albumin reduces ischaemia/ reperfusion injury in the pig heart after unprotected warm ischaemia. Cardiovasc. Res. 77, 506-514 (2008).

32. Saavedra, J. E. et al. Localizing antithrombotic and vasodilatory activity with a novel, ultrafast nitric oxide donor. J. Med. Chem. 39, 4361-4365 (1996).

33. Seddon, M., Shah, A. M. \& Casadei, B. Cardiomyocytes as effectors of nitric oxide signalling. Cardiovasc. Res. 75, 315-326 (2007).

34. Lindberg, R. A., Dewhirst, M. W., Buckley, B. J., Hughes, C. S. \& Whorton, A R. $\mathrm{Ca}^{2+}$-dependent nitric oxide release in endothelial but not $\mathrm{R} 3230 \mathrm{Ac}$ rat mammary adenocarcinoma cells. Am. J. Physiol. 271, C332-C337 (1996).

35. Lückhoff, A., Pohl, U., Mülsch, A. \& Busse, R. Differential role of extra- and intracellular calcium in the release of EDRF and prostacyclin from cultured endothelial cells. Br. J. Pharmacol. 95, 189-196 (1988).

36. Grynkiewicz, G., Poenie, M. \& Tsien, R. Y. A new generation of $\mathrm{Ca}^{2+}$ indicators with greatly improved fluorescence properties. J. Biol .Chem. 260, 3440-3450 (1985).

37. Zimmermann, T., Marrison, J., Hogg, K. \& O’Toole, P. Clearing up the signal spectral imaging and linear unmixing in fluorescence microscopy. Methods Mol. Biol. 1075, 129-148 (2014).

38. Hunter, R. A., Storm, W. L., Coneski, P. N. \& Schoenfisch, M. H. Inaccuracies of nitric oxide measurement methods in biological media. Anal. Chem. 85, 1957-1963 (2013).

39. Ignarro, L. J., Byrns, R. E., Buga, G. M. \& Wood, K. S. Endothelium-derived relaxing factor from pulmonary artery and vein possesses pharmacologic and chemical properties identical to those of nitric oxide radical. Circ. Res. 61, 866-879 (1987). 
40. Bryan, N. S. \& Grisham, M. B. Methods to detect nitric oxide and its metabolites in biological samples. Free Radic. Biol. Med. 43, 645-657 (2007).

41. Espey, M. G., Miranda, K. M., Thomas, D. D. \& Wink, D. A. Ingress and reactive chemistry of nitroxyl-derived species within human cells. Free Radic Biol. Med. 33, 827-834 (2002).

42. Zhang, J., Campbell, R. E., Ting, A. Y. \& Tsien, R. Y. Creating new fluorescent probes for cell biology. Nat. Rev. Mol. Cell Biol. 3, 906-918 (2002).

43. Chudakov, D. M., Matz, M. V., Lukyanov, S. \& Lukyanov, K. A. Fluorescent proteins and their applications in imaging living cells and tissues. Physiol. Rev. 90, 1103-1163 (2010).

44. Okumoto, S. Imaging approach for monitoring cellular metabolites and ions using genetically encoded biosensors. Curr. Opin. Biotechnol. 21, 45-54 (2010).

45. Pearce, L. L. et al. Role of metallothionein in nitric oxide signalling as revealed by a green fluorescent fusion protein. Proc. Natl Acad. Sci. USA 97, 477-482 (2000).

46. Koesling, D., Russwurm, M., Mergia, E., Mullershausen, F. \& Friebe, A. Nitric oxide-sensitive guanylyl cyclase: structure and regulation. Neurochem. Int. 45, 813-819 (2004)

47. Krumenacker, J. S., Hanafy, K. A. \& Murad, F. Regulation of nitric oxide and soluble guanylyl cyclase. Brain Res. Bull. 62, 505-515 (2004).

48. He, W. L., Feng, Y., Li, X. L., Wei, Y. Y. \& Yang, X. E. Availability and toxicity of $\mathrm{Fe}(\mathrm{II})$ and $\mathrm{Fe}(\mathrm{III})$ in Caco-2 cells. J. Zhejiang Univ. Sci. B 9, 707-712 (2008).

49. Poburko, D. \& Demaurex, N. Regulation of the mitochondrial proton gradient by cytosolic $\mathrm{Ca}^{2}$ signals. Pflugers Arch. 464, 19-26 (2012).

50. Waldeck-Weiermair, M. et al. Molecularly distinct routes of mitochondrial $\mathrm{Ca}^{2+}$ uptake are activated depending on the activity of the sarco/endoplasmic reticulum $\mathrm{Ca}^{2+}$ ATPase (SERCA). J. Biol. Chem. 288, 15367-15379 (2013).

51. Malli, R., Frieden, M., Hunkova, M., Trenker, M. \& Graier, W. F. Ca ${ }^{2+}$ refilling of the endoplasmic reticulum is largely preserved albeit reduced $\mathrm{Ca}^{2}+$ entry in endothelial cells. Cell Calcium. 41, 63-76 (2007).

52. Malli, R., Frieden, M., Trenker, M. \& Graier, W. F. The role of mitochondria for $\mathrm{Ca}^{2+}$ refilling of the endoplasmic reticulum. J Biol Chem. 280, 12114-12122 (2005).

53. Shiva, S. Nitrite: a physiological store of nitric oxide and modulator of mitochondrial function. Redox Biol. 1, 40-44 (2013).

54. Ghafourifar, P. \& Cadenas, E. Mitochondrial nitric oxide synthase. Trends Pharmacol. Sci. 26, 190-195 (2005).

\section{Acknowledgements}

We thank C.J. Edgell, Pathology Department, University of North Carolina at Chapel Hill, NC, USA, for providing us the EA.hy926 cells. We acknowledge the technical assistance of Anna Schreilechner and Petra Lang from the Medical University of Graz. E.E. is supported by Nikon Austria within the Nikon-Center of Excellence Graz and is a fellow of the PhD program Molecular Medicine at the Medical University of Graz. B.G. and C.T.M.-S. are funded by the FWF (W 1226-B18, DKplus Metabolic and Cardiovascular Disease), and this work was also funded by the FWF project P 28529-B27 at the Medical University of Graz. S.C. and E.E. are doctoral fellows of the doctoral school Molecular Medicine at the Medical University of Graz. Microscopic equipment is part of the Nikon-Center of Excellence Graz that is supported by the Austrian infrastructure program 2013/2014, Nikon Austria Inc., and BioTechMed, Graz.

\section{Author contributions}

E.E. conceived the idea, designed the constructs, and performed the imaging experiments and data analysis. B.G., S.C. and S.B. performed the imaging and image analysis. H.B. generated the mitochondria-targeted geNOps, GPI-anchored C-geNOp and characterized the constructs. C.T.M-S. tested cell viability and metabolic activity, R.R. organized cell culture, cell transfection and tested probes. B.P. isolated and cultured cardiomyocytes. W.S. and E.B. cultured and transfected glioblastoma cells. S.H. generated S-NO-HSA and together with T.M. designed and performed the nitric oxide measurements using a nickel porphyrin/nafion-modified carbon fibre microelectrode. M.W.-W. designed the cloning strategies, and performed cloning and imaging experiments. W.F.G. together with E.E. and R.M. conceived and designed the study, interpreted the data and wrote the manuscript.

\section{Additional information}

Supplementary Information accompanies this paper at http://www.nature.com/ naturecommunications

Competing financial interests: E.E., M.W.-W., R.M. and W.F.G. have filed a UK patent application (patent application number 1419073.0) that describe parts of the research in this manuscript. This does not alter the authors' adherence to all of the Nature Communications policies on sharing data and materials presented in this manuscript. The remaining authors declare no competing financial interests.

Reprints and permission information is available online at http://npg.nature.com/ reprintsandpermissions/

How to cite this article: Eroglu, E. et al. Development of novel FP-based probes for live-cell imaging of nitric oxide dynamics. Nat. Commun. 7:10623 doi: 10.1038/ncomms10623 (2016)

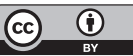

This work is licensed under a Creative Commons Attribution 4.0 International License. The images or other third party material in this article are included in the article's Creative Commons license, unless indicated otherwise in the credit line; if the material is not included under the Creative Commons license, users will need to obtain permission from the license holder to reproduce the material. To view a copy of this license, visit http://creativecommons.org/licenses/by/4.0/ 